\title{
Measuring Social Capital in Creative Teams Through Sociometric Sensors
}

\section{Peter A. Gloor ${ }^{1}$, Francesca Grippa ${ }^{2}$, Johannes Putzke $^{3}$, Casper Lassenius ${ }^{4}$, Hauke Fuehres ${ }^{3}$, Kai Fischbach ${ }^{5}$, Detlef Schoder ${ }^{3}$}

${ }^{1}$ MIT Center for Collective Intelligence, 5 Cambridge Center, Cambridge MA 02139 ${ }^{2}$ Northeastern University

3University of Cologne,

${ }^{4}$ Aalto University

5University of Bamberg

E-mail:pgloor@mit.edu

E-mail: f.grippa@neu.edu

E-mail: putzke@wim.uni-koeln.de

E-mail: Casper.Lassenius@tkk.fi

E-mail: fuehres@wim.uni-koeln.de

E-mail: kai.fischbach@uni-bamberg.de

E-mail: schoder@wim.uni-koeln.de

\begin{abstract}
We describe the results of an experiment capturing the face-to-face "honest signals" of knowledge workers through sociometric badges. We find that collective creativity of teams is a function of the aggregated social capital of members. The higher it is, the higher their creative output. We collected communication data of 14 graduate students and their instructor during a one-week seminar, comparing it against the creative output of their teamwork. As a second component of social capital we also measured the level of trust team members show to each other through surveys. We find that the more team members directly interact with each other face-to-face, and the more they trust other team members, the more creative and of higher quality the result of their teamwork is.
\end{abstract}

Keywords: Sociometric badges, creativity, social network analysis, trust, small teams, knowledge worker productivity, social capital

Biographical notes: Peter A. Gloor is a Research Scientist at the MIT Center for Collective Intelligence.

Francesca Grippa is an Assistant Academic Specialist at the Northeastern University College of Professional Studies. 


\section{P. Gloor et. al.}

Johannes Putzke is an Assistant Professor at the University of Cologne.

Casper Lassenius is a Professor at the Software Business and Engineering Institute at Aalto University, Helsinki.

Hauke Fuehres is a Ph.D candidate at University of Cologne.

Kai Fischbach is a Professor and Chair in Information Systems and Social Networks at the University of Bamberg.

Detlef Schoder is a Professor and Chair in Information Systems and Information Management at the University of Cologne.

\section{Introduction}

Analyzing and understanding individual and team creativity has been a longstanding area of research, extending the view of human ability and achievement beyond the traditional concept of intelligence. Creativity is defined by Csikszentmihalyi (1997) as an act, idea, or product that changes an existing domain - which can be anything from nursing to nuclear physics - or that transforms an existing domain into a new one. In this paper we address the topic of organizational and team creativity, looking at interventions that might make groups of people more creative. What distinguishes a particularly creative individual from others? According to Csikszentmihalyi (1997) there are three different types of individual creativity. The first one is applied to any person that expresses interesting and novel ideas. A bright conversationalist, a person with varied interests, who appears highly intelligent, is commonly called "creative". Csikszentmihalyi calls these people "brilliant". The second group is composed of the "personally creative" people, having insightful judgment and making important discoveries recognized by the outside world. Undoubtedly the most interesting ones are people in the third category whom Csikszentmihalyi adorns with the capital " $\mathrm{C}$ " of Creativity, like Leonardo da Vinci, Thomas Alva Edison, or Pablo Picasso, who have changed our culture in some important aspect. In this paper we focus on the latter two categories of creativity. While not everybody can be a Leonardo, Edison, or Picasso, groups, companies and organizations rely on creativity that is recognized by others.

Ultra-creative people share some contradicting common traits according to Csikszentmihalyi (1997). They have high physical energy, but are also quite often at rest. They are smart but naïve, with an IQ of at least 120 . They combine playfulness and discipline, fantasy and reality, extroversion 
and introversion, masculine and feminine traits. They are both humble and proud at the same time, rebellious and independent, and passionate but objective. In this paper we introduce a set of tools and methods that try to capture some of these characteristics by measuring communication patterns between people.

Highly creative processes happen in a state of flow. Flow experiences can emerge in many different situations. Whether it is in sports, music, conversation, sex, or creating a new product, the state of flow is immensely rewarding: the individual is not looking for any external rewards anymore; just the fact of being immersed into the activity is reward enough. The interesting point, however, is that it always takes other people for a person to reach the state of flow (Collins 2005). While the other people do not have to be physically present, they are nevertheless present in the mind of the person reaching the flow state. In this paper we extend Csikszentmihalyi's concept of individual creativity and flow to the level of group creativity and group flow, trying to understand what personality characteristics are supportive of getting creative groups into the flow state.

\section{Background -Individual Characteristics Influence Group Creativity}

Initial research on organizational creativity focused on the individual actor and investigated personality traits of highly creative people (Barron and Harrington, 1981; Helson, 1996). Creativity has been defined by organizational researchers based on the novelty and usefulness of ideas generated by individuals and groups (Amabile, 1983, Csikszentmihalyi, 1997). One of the most widely recognized theories of organizational creativity - known as the componential model of creativity - has been proposed by Teresa Amabile (1983). This theory explains the interactions of social and environmental factors with personality characteristics and the effects of these factors on observable creativity. Amabile identifies three factors that might influence organizational creativity: organizational motivation to innovate, resources, and management practices. The interactional perspective on creativity suggests that the effective translation of ideas into action will depend on a variety of individual and situational attributes such as motivation, skills, personality, and contextual features (Zhou et al., 2009; Woodman et al., 1993).

\subsection{Social Networks To Discover New Ideas}

Individual cognitive biases may constrain creativity. Because creativity in the organizational context involves the recombination of different existing 
ideas, researchers are looking for social sources of new ideas going beyond individual cognitive processes (Sawyer, 2009). Social networks are recognized as a powerful tool for accessing diverse and contrasting ideas. Uzzi and Spiro (2005) studied the creativity of artists on Broadway musicals from 1945 to 1989 . They found that a combination of previous collaborations among artists and network diversity - represented by newcomers to the team - was correlated with box office success. On the negative side, authors recognize that social networks can act as channels to reinforce groupthink and limit individual perspectives (Perry-Smith and Shalley, 2003; Amabile, 1988; Ferrin and Shah, 1997).

While the importance of social capital represented through social networks (Putnam 2001) has been widely recognized in literature, there is still a lack of formally defined measurement systems to quantitatively detect how ideas develop and what factors foster their development.

\subsection{Individual Attributes of Group Creativity}

A limitation of the social network perspective is that researchers might focus exclusively on relationships rather than including attributes of actors, not considering how individual characteristics may interact with the structural characteristics of the groups. To address this limitation, our research combines face-to-face interaction and personal characteristics. As demonstrated by extensive research (Barron, 1969; Amabile, 1983, 1996) creative individuals are characterized by specific personality traits: self-confidence, independence of judgment, attraction to complexity, risk taking. Some authors (Feist, 1999) suggest that the creative individual is distinguished by qualities like independence, asocial behaviors, introversion, hostility, and arrogance. Other authors highlight more positive traits: openness to experience, ambition, flexibility of thought and active imagination and a high level of energy to challenge the established norms (Amabile, 1996; Sternberg and Lubart, 1995).

\subsection{Trust as an Ingredient for Group Creativity}

By investigating the influence of social networks and conformity value on employees' creativity, Zhou et al. (2009) found that when creative coworkers were working in the same group, the less supervisors engaged in close monitoring, the more employees exhibited creativity. This means that trust is a key ingredient for successful group creativity. Researchers in the areas of psychology and organizational behavior have been investigating the role of trust in determining group performance (Dirks, 1999; McAllister, 1996; Friedlander, 1970). As these studies indicate, trust 
might increase the ability of group members to work together more effectively and efficiently. Because trust may improve the willingness to cooperate and work towards common goals, effectiveness is expected to increase. At the same time, trust might impact positively on efficiency because of the reduced need for rules and monitoring mechanisms. Dirks (1999) found that trust might influence group performance in an indirect way: "Groups with higher levels of trust did not necessarily have better processes and better performance than groups with low levels of trust. Instead, trust appeared to influence how motivation was translated into group process and performance" (Dirks, 1999, p. 453). A recent study by Ferrin, Dirks and Shah (2006) indicates that third-party relationships act as a force that influences trust by shaping interpersonal behavior, as individuals draw on third parties to inform their trust judgments. Their study indicates an increasing interest in understanding trust in the network context, yet little empirical research exists on the factors determining interpersonal trust in an organizational network. In our research, we investigate trust and the willingness of actors to trust others as a characteristic of an individual and of a group.

\section{4 "Honest Signals" of Creative Team Members}

Based on the personality characteristics of creative people introduced above, our work explores what behavior might be indicative of these personality characteristics, and what might be done to reinforce behaviors that can affect the quality of a group endeavor. Our study relies on seminal work done by Sandy Pentland $(2007,2008)$ and his team on "honest signals". These signals are an important component of individual behavior, as they are unconscious signs that individuals exhibit during social interactions. Pentland measured these honest signals by analyzing body movement patterns, and the timing, energy, and variability of speech. According to Pentland (2008), there are four types of honest signals: (1) influence, which means the extent to which someone causes the other person's pattern of speaking to match their own pattern; (2) mimicry, the automatic copying of one person by another during a conversation; (3) activity, represented by the energy and the time spent in a conversation; and (4) consistency, which is measured through low variability in the speech signal.

Experiments to measure and model organizational behavior at the individual and group level using sociometric badges have already been conducted in a variety of settings (Olguín-Olguín et al., 2009; OlguínOlguín and Pentland, 2010). Sociometric badges are wearable electronic sensors capable of detecting face-to-face interactions, conversations, body 
movement, and physical proximity (Olguín-Olguín, 2007). Based on experimental data collected within a German bank, a large hospital in the Boston area and a bank in the Czech Republic, Olguín-Olguín et al. (2010) found that social signaling behavior and face-to-face network characteristics can predict group performance. This stream of work has demonstrated the benefits of using automatic methods to collect data on human behavior. Whereas surveys might be time consuming and subjective, and the use of cameras to videotape humans can be both intrusive and expensive, measuring group behavior with unobtrusive sensors offers the advantage to automatically capture and store data from groups of people.

\subsection{Measuring Creativity}

Many researchers mix up performance and creativity, assuming that a high-performing group or individual must be more creative (Hackman and Katz, 2010). One framework to analyze creative output of small groups measures fluency and flexibility, fluency referring to the number of nonredundant ideas, and flexibility referring to the number of idea categories represented in ideas (Choi and Thompson, 2005). Goncalo and Staw (2006) recently studied group creativity and the effect of individualistic and collectivistic values. In a laboratory setting people were asked to generate ideas in a 15 minute period, while two additional coders rated each idea for creativity based on criteria of originality and novelty. This subjective rating of creativity can be considered a limitation of this type of study. Simply counting the number of different ideas and idea categories does not really account for the impact and quality of the creative ideas.

Frequently results of creativity take some time to come to fruition. For example, Cummings and Kiesler (2008) studied the success of over 500 interdisciplinary research projects sponsored by NSF. They found that while distance of interdisciplinarity reduces creative output, prior collaboration mitigates this effect. They measured creative output of the teams in four dimensions: knowledge (e.g. publications), tools (e.g. software), training (e.g. Ph.D students), and outreach (e.g. museum installations). Their results illustrate that just ranking the number of creative tasks is a poor predictor for long-term creativity. High performance in generating many different low-quality ideas might have less impact in the long term. To reduce this bias, and inspired by United States Supreme Court Justice Potter Stewart's quote describing pornography as "I know it when I see it," we are using peer-rating as our method to assess the quality and novelty of ideas, assuming that people "know creativity when they see it." 


\section{Method}

During a 5-day graduate student block seminar with 15 participants taught in June 2010 at the University of Cologne, we compared "honest signals" (Pentland 2008) captured with sociometric badges (Olguin 2007) with the creativity and quality of the teamwork of the participants.

The goal of the seminar was to study a wide range of methods for predictive analytics, mostly based on social network analysis and the emerging science of collaboration. Participants were doctoral students of information systems, computer science, sociology, economics, psychology, and related fields. During the course, small teams of two to four students presented an overview of research topics based on previous readings. In the afternoons small student teams in changing composition worked on their own trend analysis and prediction projects whose results were presented at the last course day. The literature review presentations and the final project presentations were peer rated by the non-presenting students on two dimensions, creativity and quality. As demonstrated by other researchers (Falchikov, 1986), peer-assessment can be considered a reliable and valid method to assure individual accountability.

\subsection{Measuring Social Network Position with Sociometric Badges}

While the students worked together for eight hours per day, they also wore the sociometric badges introduced above to capture their own communication behavior (Figure 1). 
P. Gloor et. al.

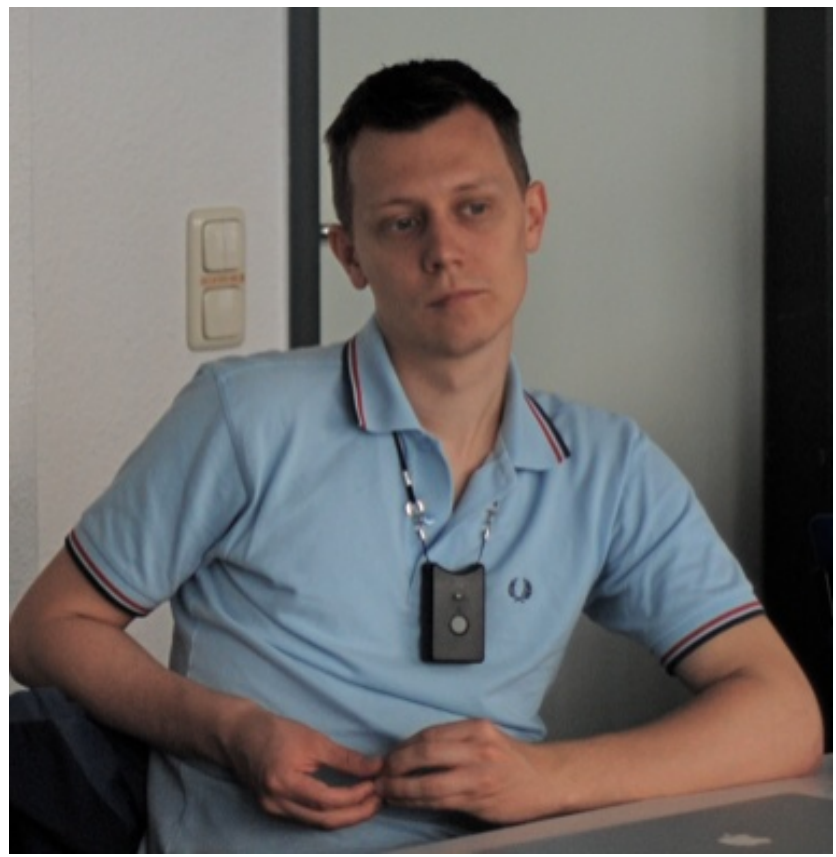

Figure 1. Sociometric Badge

These badges capture four types of signals. Radio sensors capture physical proximity between badges, infrared (IR) sensors measure if two badge wearers are facing each other, which also means that they are looking at each other. The badges also have built in microphones to capture voice and pitch patterns - the content of what is said is not captured. An accelerometer measures the energy levels of the wearer. In this paper we only use the first two types of signals: the ones captured by the radio and by the IR sensors. Based on the IR and radio signals of the badges we construct two social networks. The first network aggregates signals collected with the IR sensors, where one interaction is measured if actor A is facing actor $\mathrm{B}$. The second network is constructed using the radio sensors, taking one reading if actor $\mathrm{A}$ is closer than a threshold (about 1.5 meters) to actor B. For each actor in the network, we calculated three social network analysis metrics (Wasserman and Faust, 1994). The first metric is degree centrality which measures the number of nearest neighbors of each actor. The second is betweenness centrality that measures information flow through the network by measuring the probability that an actor is on the shortest path connecting any two actors. Betweenness is commonly considered a measure for the influence of an actor. As our network is quite small, we are using weighted betweenness centrality (Opsahla et al., 2010). The third metric we compute is the contribution index of each actor, which measures the propensity of an 
actor to be a sender or a receiver of a signal (Gloor et al., 2003). This metric is only accurate for the IR network, because the angles of the IR sender beacon and IR receiver in the sociometric badge are different. Through the IR sensors, the contribution index therefore measures how much somebody is being looked at compared to how much s/he looks at others.

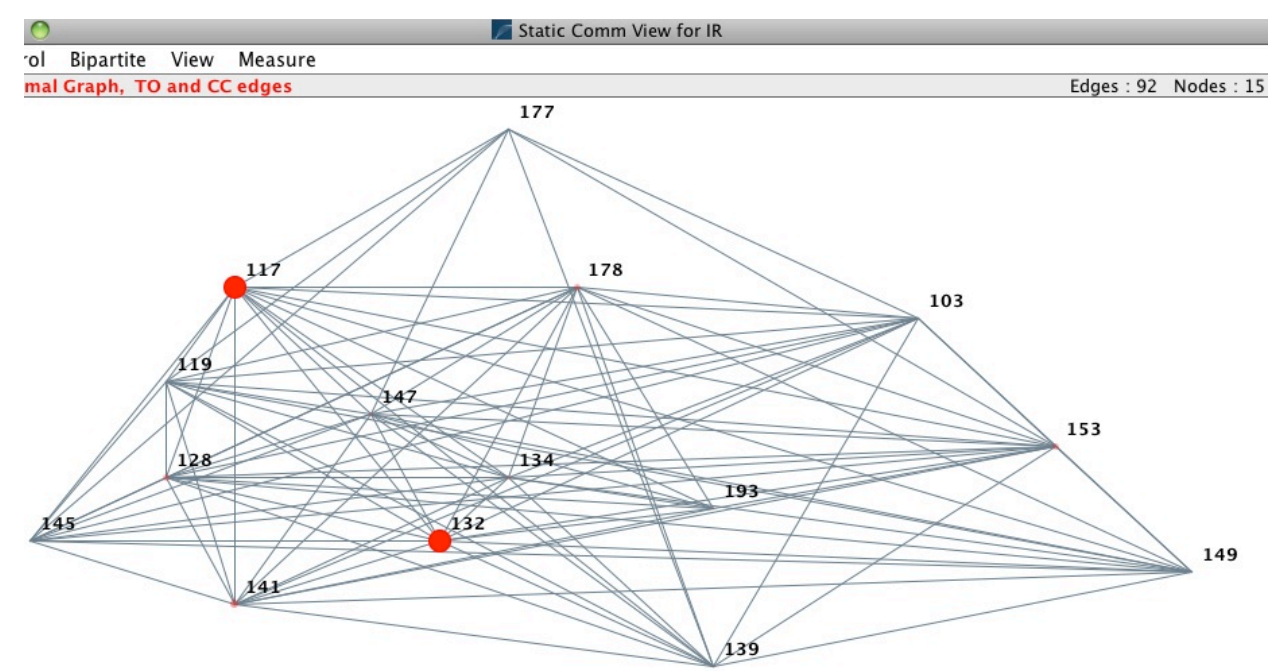

Figure 2. IR network of full week (circles show weighted betweenness centrality)

Figure 2 displays the IR network, aggregating all signals collected when two people faced each other over the entire 5-day period. As can be seen, actors 117 and 132 have the highest betweenness centrality, actor 132 being the instructor, and actor 117 a student. 


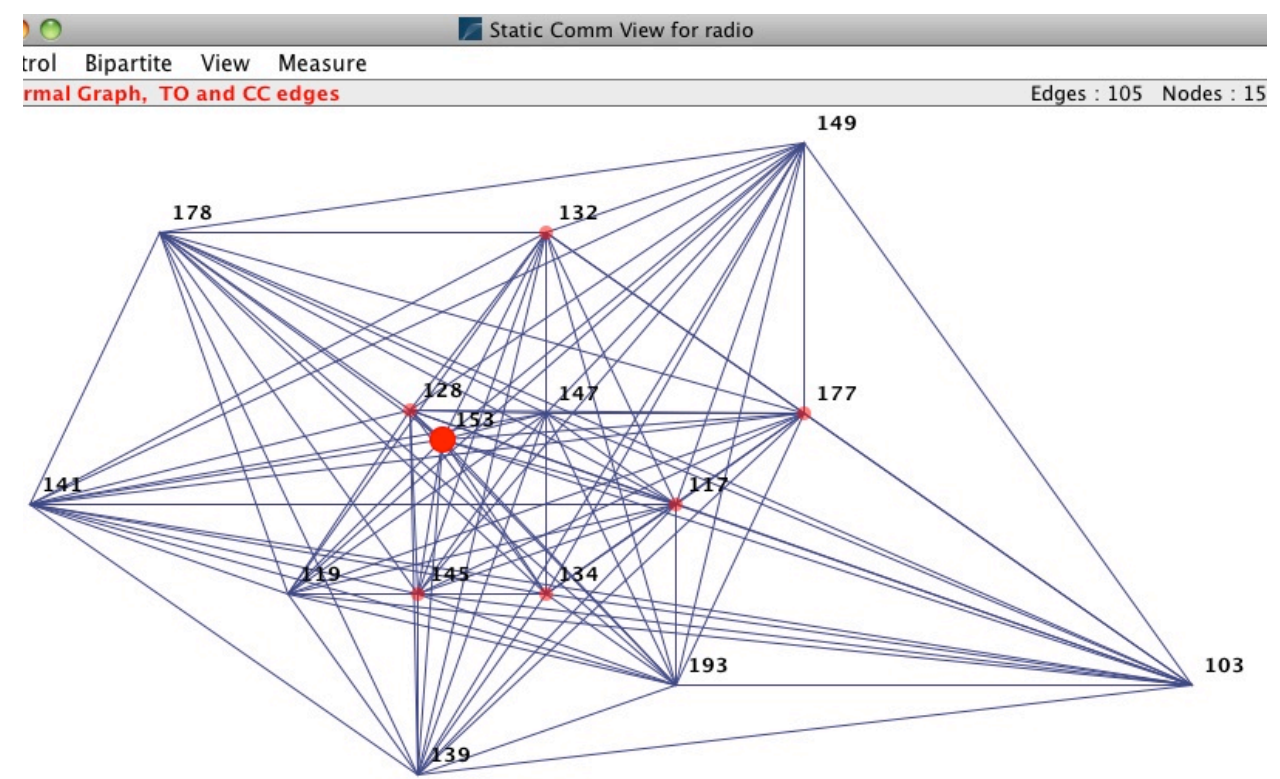

Figure 3. Radio network of full week (circles show weighted betweenness centrality)

Figure 3 displays the radio network, aggregating all collected signals over the 5-day period. As can be seen, actor 153 has the highest betweenness centrality. His position in the confidence and non-confidence network (see figure 4 below), as well as in the IR network is quite low. This already illustrates that having a lot of physically close interaction does not predict a prominent position in the group.

We also counted the total number of times team members of each team were facing each other during the entire week using the infrared sensors. Note that this also includes times when participants were having lunch in the cafeteria, or were taking a break, as they were wearing the sensors from morning to the evening. This is different from constructing the social network shown in figure 2, and simply measures pair-wise interaction. These accumulated IR signals of a badge with all other actors can be interpreted as a proxy for the social capital the sociometric badge wearer collected over the week. We exclude the radio network from the social capital construct because the IR signals (and therefore the eye contact) are more appropriate to approximate the knowledge exchanged in a team. Our assumption is that looking at each other is a more powerful indicator of the social capital than just being in proximity to one another. 


\subsection{Measuring Trust - the Confidence Network}

In addition, every evening the students filled out a series of daily surveys. Among others, they also answered the following question to measure trust: "There are some people in our daily lives with whom we are willing to share personal confidences. How likely would you be to share personal confidences with the following persons?" on a scale from -3 (very unlikely) to +3 (very likely). This question was answered three times, on Monday, Wednesday, and Friday. For the analysis, the answers were split in links rated $>=0$ (willingness to confide), and $<0$ (unwillingness to confide). In this project we take the cumulated answers to this question as a proxy of pre-existing social capital of a person.

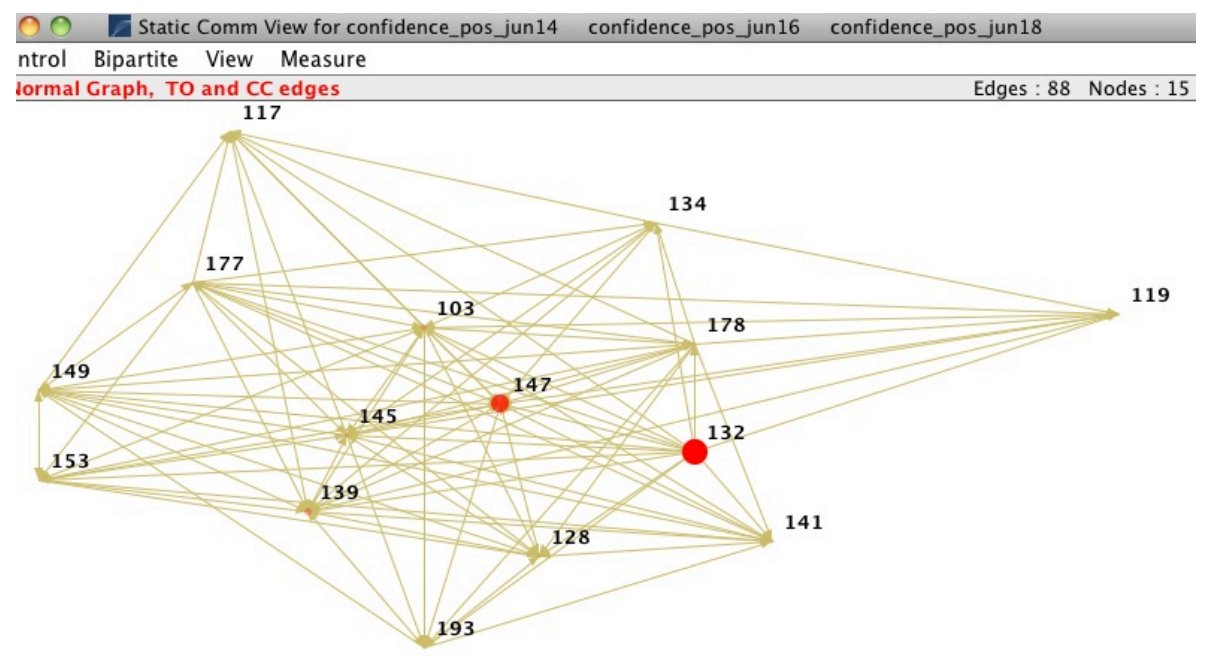

Figure 4. Confidence Network of full week (weighted betweenness centrality)

Figure 4 displays the confidence network aggregated over three surveys taken June 14, 16, and 18 i.e. at the beginning, half-way, and end of the course. Links are directed, denoting how much one actor is willing to confide into another. Although there is a link between almost any two actors, their weighted betweenness centrality can vary substantially, as does the directionality of the tie. 


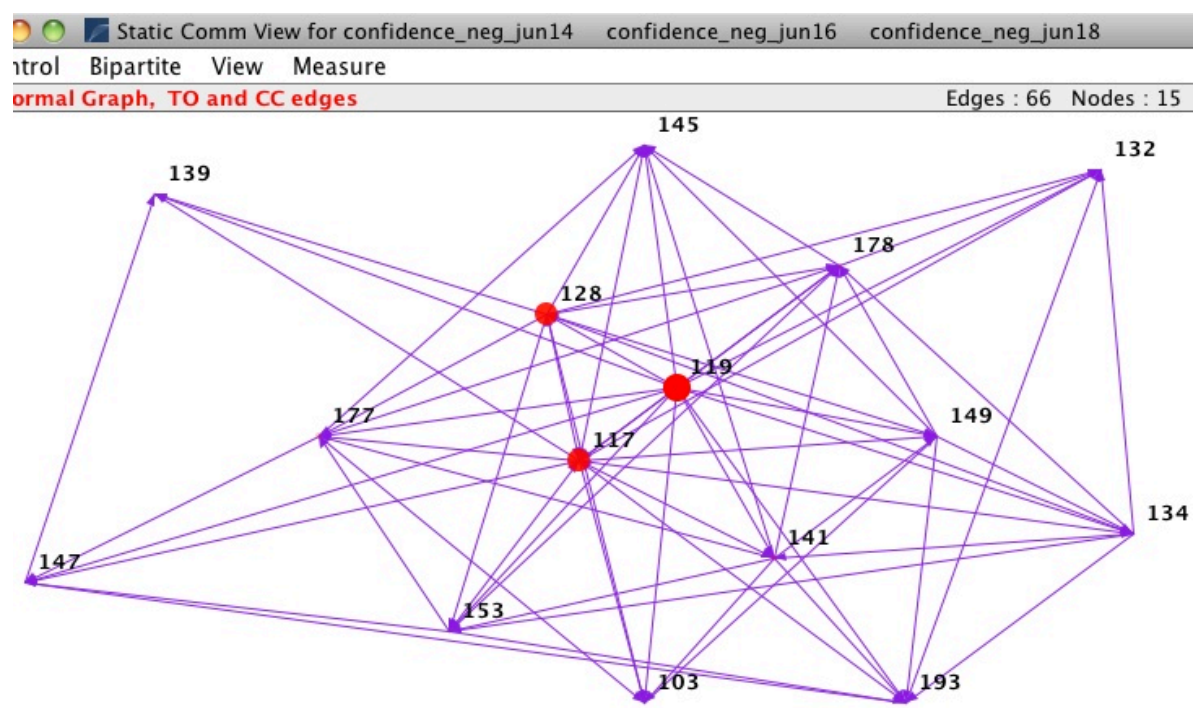

Figure 5. Non-confidence network of full week (weighted betweenness centrality)

Figure 5 displays the non-confidence network aggregated over the same three surveys taken June 14, 16, and 18. Links are directed, denoting how much one actor is unwilling to confide into another.

Similarly to IR interaction, we also summed up all expressions of trust an actor got by others as a second proxy for a priori social capital.

\subsection{Measuring Creativity}

Defining and rating creativity is known to be a hard problem, in the past a wide range of definitions has been used (Csikszentmihalyi, 1997). We have used peer-rating, asking the course participants to rate the quality and creativity of the team output of their peers, assuming they will "know creativity when they see it".

Based on findings by Choi and Thompson (2005) we mixed the composition in the teams for the different tasks. It had been found earlier that particularly for complex knowledge-intensive tasks changing team membership should have beneficial effects (Ancona et al., 2002). Each participant worked in at least two teams, all teams presented their results to the entire course. For each presentation, the other participants ranked the work of the team on two dimensions, creativity and quality, on a Likert scale of 1 (worst) to 5 (best). Figure 6 lists the basic statistics of the 9 projects. 


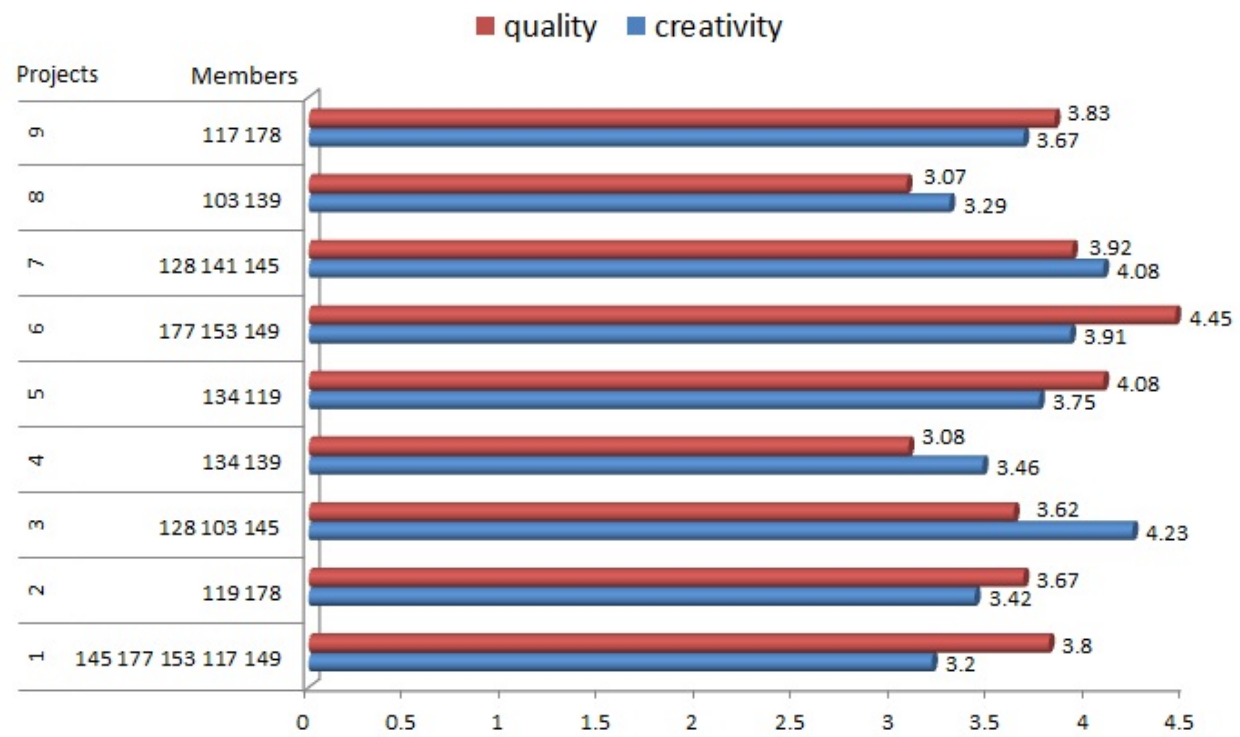

Figure 6. Projects and Basic Metrics of creativity and quality

In addition each participant also completed the NEO-FFI survey (Hough, 1992). The NEO-FFI is a personality test to measure five independent domains of personality: neuroticism (tendency to experience negative emotions like fear, sadness, or anger); extraversion (tendency to be social and to experience positive emotions); openness to experience (attentiveness to inner feelings, active imagination, intellectual curiosity); conscientiousness (being organized, competent, thoughtful, and motivated) and agreeableness (prosocial behaviors like trust, modesty, and altruism).

\section{Hypothesis}

Our project addresses the interplay between personality characteristics, trust, face-to-face interaction captured through the IR sensor of the sociometric badges, and team creativity. In prior work we had found that humans like to look at people they trust (Gloor et al., 2010). In parallel, we had also found that these "honest signals" are reliable predictors of individual personality characteristics (Gloor et al., 2010, Olguin et al., 2009). On the other hand we speculate that trust between team members might be a pre-condition for team creativity, because only if team members are not forced to show a façade, and collaborate in an 
environment of mutual trust will they be willing to mention "crazy ideas". Trust will therefore take away the risk of ridicule.

In earlier work measuring the quality of the work of Wikipedians (Nemoto et al., 2011), we had found that the more social capital in the form of positive pre-existing collaborative relationships Wikipedians had, the higher the quality of their work. In this project we take the accumulated IR sensor interactions between team members and the expressions of trust as proxies for newly developed and pre-existing social capital.

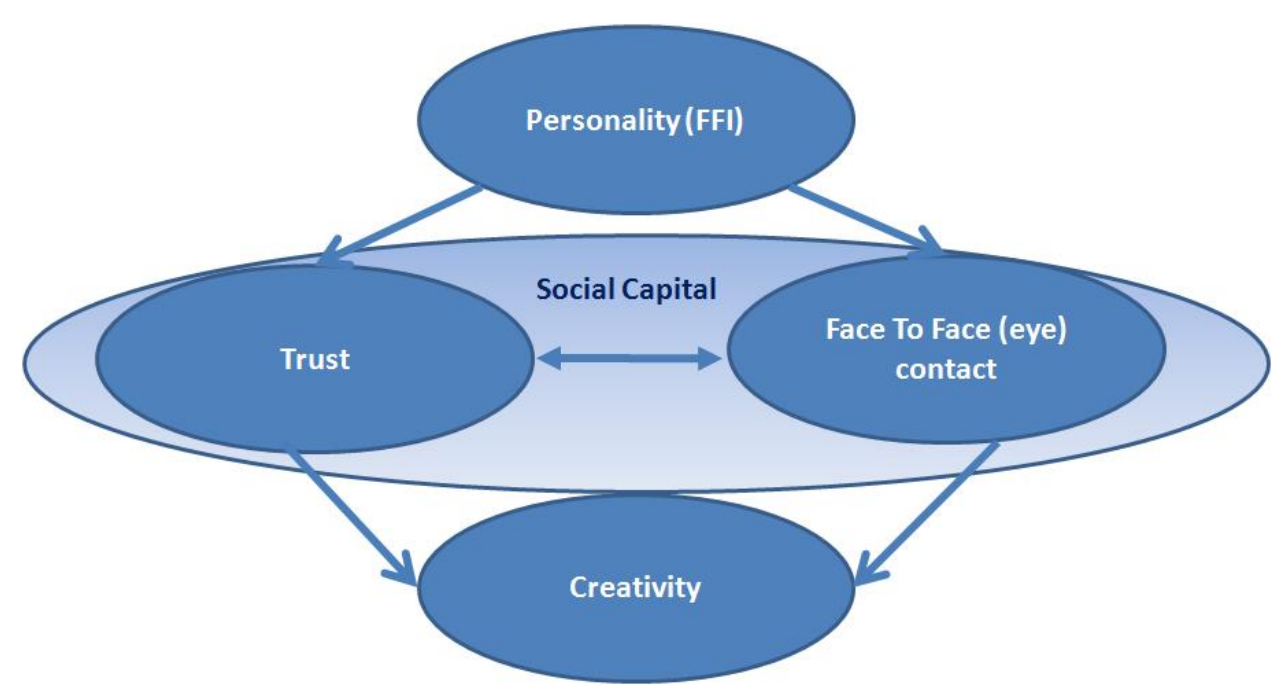

Figure 7. Evaluation Framework

Figure 7 illustrates the evaluation framework: individual personality characteristics (measured through the FFI Test) influence behavior such as looking each other into the eyes when talking to each other. Personality characteristics also influence the propensity of people to trust others and to be trusted. For example, we would expect that more open people are more trusting, and that more agreeable and conscientious people are more trusted. We speculate that the teams where people trust each other most, and where they interact most directly and frankly by accumulating most interactions will be the most creative. We therefore formulate the following hypothesis:

Hypothesis: the higher the accumulated social capital of a team, measured as the sum of the expression of trust between team members, and the amount of interaction between team members, the higher the creativity and quality of their team output. 
This means that we study prerequisites of team creativity, exploring the variables impacting the ability of groups to deliver results of high quality and high creativity. In particular, we analyze how personality characteristics influence the social network position of an actor. We also investigate how the social network position in a face-to-face network influenced by personality characteristics - predicts mutual trust. A high level of mutual trust, as indicated by social network position should then predict higher team creativity. The goal is to gather empirical evidence to verify the hypothesis that both trust between team members and the amount of interaction between them are correlated with higher collective creativity.

\section{Results}

\subsection{Personality and social network position in the f2f network}

Comparing the social network position in the face-to-face network measured with the IR sensors with FFI personality characteristics, we find that more open people are more central in the network.

\begin{tabular}{|ll|l|l|l|}
\hline & & \multicolumn{1}{|c|}{ ci } & mean abc & mean adc \\
\hline neuroticism & Pearson & -.147 & -.481 & -.090 \\
& Sig. (2-tailed) & .633 & .096 & .769 \\
& $\mathrm{~N}$ & 13 & 13 & 13 \\
\hline extroversion & Pearson & -.124 & $-.867^{* *}$ & $-.847^{* *}$ \\
& Sig. (2-tailed) & .687 & .000 & .000 \\
& $\mathrm{~N}$ & 13 & 13 & 13 \\
\hline \multirow{2}{*}{ openness } & Pearson & -.071 & .509 & .538 \\
& Sig. (2-tailed) & .818 & .076 & .058 \\
& $\mathrm{~N}$ & 13 & 13 & 13 \\
\hline agreeability & Pearson & -.517 & .286 & .546 \\
& Sig. (2-tailed) & .070 & .344 & .054 \\
& $\mathrm{~N}$ & 13 & 13 & 13 \\
\hline conscientiousness & Pearson & .166 & $.612^{*}$ & .422 \\
& Sig. (2-tailed) & .589 & .026 & .150 \\
& $\mathrm{~N}$ & 13 & 13 & 13 \\
\hline
\end{tabular}

Table 1. Correlations between FFI personality characteristics and f2 f network position (ci=contribution index over entire week, mean_abc=mean actor betweenness centrality aggregated per day, mean_adc=mean actor degree centrality per day, $r,{ }^{*}=$ significant on 0.05 level, $* *=$ significant on 0.01 level)

The more extrovert people are, the lower is their mean degree and betweeness centrality. This seems to indicate that highly extrovert people might be less popular in face-to-face interaction. 
The higher the mean betweenness and degree centrality of people in the face-to-face network is, measured by the IR sensors, the more open they are for new things. This means that interacting with many central people predicts openness for new things.

The lower the contribution index is (the more a person is being looked at), the more agreeable $\mathrm{s} / \mathrm{he}$ is. The higher face-to-face mean betweenness centrality of a person, the more agreeable $\mathrm{s} / \mathrm{he}$ is. This means that people prefer interacting with agreeable people, which is likely due to the cooperative and non-competitive attitude often associated with agreeability.

The higher face-to-face mean betweenness centrality of a person, the more conscientious $\mathrm{s} / \mathrm{he}$ is. This means that people prefer interacting with others showing constant and predictable behavior.

These results confirm similar earlier results we had obtained when collecting sociometric badge data and comparing it with the FFI test results in the marketing department of a German bank (Gloor et al., 2010) and the Post Anesthesia Care Unit of a large Boston hospital (Olguin et al., 2009).

\subsection{Trust and social network position in the f 2 f network}

To calculate the trust-component of social capital of each actor, the social networks of confidence and non-confidence are compared against the social network position collected by the sociometric badges. Using QAP correlation in Ucinet (Borgatti 2002) we find that the IR and radio networks are correlated $\left(\mathrm{R}=0.237^{*}\right)$, and that the confidence and IR networks are correlated, too $\left(\mathrm{R}=0.161^{*}\right)$, which means that people who are more central in the network of trust are also more central in the face-toface network. As is to be expected, the confidence and non-confidence networks are negatively correlated $\left(\mathrm{R}=-0.358^{* * *}\right)$.

\begin{tabular}{|l|l|l|l|}
\hline & Radio network & $\begin{array}{l}\text { Confidence } \\
\text { network }\end{array}$ & $\begin{array}{l}\text { Non-confidence } \\
\text { network }\end{array}$ \\
\hline IR network & 0.237 & 0.161 & 0.075 \\
$(\mathrm{p}=0.019)$ & $0.041)$ & $0.186)$ \\
\hline Radio network & & 0.007 & 0.108 \\
$(\mathrm{p}=0.482)$ & & $\begin{array}{l}\mathrm{p}=0.214) \\
(\mathrm{p}=0.000)\end{array}$ \\
\hline Confidence network & & & \\
\hline
\end{tabular}

Table 2. QAP correlation between IR network, radio network, confidence network, and non-confidence network

People who are less trusting, on the other hand, show a larger variation in their face-to-face communication. 
Measuring Social Capital in Creative Teams Through Sociometric Sensors

\begin{tabular}{|ll|r|r|r|r|r|}
\hline & & & & $\begin{array}{c}\text { mean } \\
\text { abc }\end{array}$ & $\begin{array}{r}\text { mean_a } \\
\text { dc }\end{array}$ & std_adc \\
\hline dc_trust_d1 & Pearson & .064 & .080 & $\mathbf{. 5 7 1}^{*}$ & .387 & -.015 \\
& Sig. (2-tailed) & .820 & .777 & .026 & .154 & .957 \\
& $\mathrm{~N}$ & 15 & 15 & 15 & 15 & 15 \\
\hline bc_trust_d1 & Pearson & .203 & .024 & $\mathbf{. 6 3 3}^{*}$ & .378 & -.125 \\
& Sig. (2-tailed) & .469 & .933 & .011 & .165 & .658 \\
& $\mathrm{~N}$ & 15 & 15 & 15 & 15 & 15 \\
\hline dc_notrust_d1 & Pearson & .026 & .127 & .038 & .390 & $\mathbf{. 6 2 5}^{*}$ \\
& Sig. (2-tailed) & .928 & .652 & .893 & .151 & .013 \\
& $\mathrm{~N}$ & 15 & 15 & 15 & 15 & 15 \\
\hline
\end{tabular}

Table 3. Correlations between trust and $\mathrm{f} 2 \mathrm{f}$ network position (abc=actor betwenness centrality over entire week, ci=contribution index over entire week, mean abc=mean actor betweenness centrality per day, mean_adc $=$ mean actor degree centrality per day, std_adc=standard deviation per day of actor betweenness centrality, dc_trust_d1=actor degree centrality on day 1 in the trust network, bc_trust_d1=actor betweeness centrality on day 1 in the trust network, dc_notrust_d1=actor degree centrality on day 1 in the distrust network )

As Table 3 illustrates, the higher face-to-face betweenness centrality of a person is, the more s/he is trusted. On the other hand, the higher the standard deviation in the face-to-face degree centrality of a person is, the less $\mathrm{s} / \mathrm{he}$ is trusted. This means, the more a person moves around, interacting with many people at one moment, and then interacting with only a few the next moment, the less s/he is trusted. It seems therefore that people trust others with constant interaction behavior more, which corresponds to the result about people with high conscientiousness described in the previous paragraph.

A similar picture emerges when analyzing the same trust and distrust data in another way, comparing the absolute numbers of face-to-face contacts with the number of statements of confidence and non-confidence they received (pos_rcvd, neg_rcvd) and gave (pos_sent, neg_sent). 


\begin{tabular}{|c|c|c|c|c|c|}
\hline & & rcvdIR & sentIR & rcvdRadio & sentRadio \\
\hline \multirow[t]{3}{*}{$\overline{\text { pos_rcvd }}$} & Pearson Correlation & .444 & .199 & .024 & .111 \\
\hline & Sig. (2-tailed) & .097 & .477 & .931 & .695 \\
\hline & $\mathrm{N}$ & 15 & 15 & 15 & 15 \\
\hline \multirow[t]{3}{*}{ pos_sent } & Pearson Correlation & .163 & -.056 & -.074 & .173 \\
\hline & Sig. (2-tailed) & .563 & .842 & .794 & .537 \\
\hline & $\mathrm{N}$ & 15 & 15 & 15 & 15 \\
\hline \multirow[t]{3}{*}{ neg_rcvd } & Pearson Correlation & -.503 & -.133 & -.178 & -.434 \\
\hline & Sig. (2-tailed) & .056 & .638 & .525 & .106 \\
\hline & $\mathrm{N}$ & 15 & 15 & 15 & 15 \\
\hline \multirow[t]{3}{*}{ neg_sent } & Pearson Correlation & $.576^{*}$ & $.680^{* *}$ & .306 & .081 \\
\hline & Sig. (2-tailed) & .025 & .005 & .267 & .774 \\
\hline & $\mathrm{N}$ & 15 & 15 & 15 & 15 \\
\hline
\end{tabular}

**. Correlation is significant at the 0.01 level (2-tailed). ${ }^{*}$. Correlation is significant at the 0.05 level (2-tailed).

Table 4. Correlations between trust ratings given and received, and signals picked up by the social badge IR and radio sensors ( $\mathrm{rcvdIR}=$ accumulated IR signals a badge picks up from others, sentIR=accumulated number of times IR signals of a badge have been picked up by other badges, rcvdRadio=accumulated radio signals a badge picks up from others, sentRadio=accumulated number of times radio signals of a badge have been picked up by other badges, pos_rcvd=number of statements of trust received, pos_sent=numbers of statements of trust given, neg_rcvd=number of statements of distrust received, neg_sent=numbers of statements of distrust given)

The more somebody gives statements of trust (the more trusting $\mathrm{s} / \mathrm{he}$ is), the more his/her badge signal is picked up by others, i.e. the more others face $\operatorname{him} /$ her $(r=0.444, p=0.097)$. The opposite is true also: the more expressions of distrust somebody gives, the more her/his signals are picked up $\left(\mathrm{r}=0.680^{* *}\right)$, and also the more $\mathrm{s} /$ he picks up others' signals $\left(\mathrm{r}=0.576^{*}\right)$. In other words, the less trusting somebody is, the more $\mathrm{s} / \mathrm{he}$ looks at others, and the more $\mathrm{s} / \mathrm{he}$ is looked at.

\subsection{Personality and trust}

Comparing network position in the trust network with the FFI personality metrics also yields some surprising results (table 5). 
Measuring Social Capital in Creative Teams Through Sociometric Sensors

\begin{tabular}{|c|c|c|c|c|c|c|c|c|c|}
\hline & & $\begin{array}{c}\text { dc_trust } \\
\text { d1 }\end{array}$ & $\begin{array}{c}\text { bc_trust } \\
\text { d1 }\end{array}$ & $\begin{array}{l}\text { de_notr } \\
\text { ust d } 1\end{array}$ & $\begin{array}{l}\text { bc_notr } \\
\text { ust d1 }\end{array}$ & $\begin{array}{l}\text { pos } \\
\text { recvd }\end{array}$ & $\begin{array}{l}\text { pos_ } \\
\text { sent }\end{array}$ & $\begin{array}{l}\operatorname{neg}_{-} \\
\text {revd }\end{array}$ & $\begin{array}{c}\text { neg_ } \\
\text { sent }\end{array}$ \\
\hline \multirow[t]{3}{*}{ neuroticism } & Pearson & -.268 & -.469 & .208 & .136 & .225 & -.403 & -.140 & .143 \\
\hline & Sig. (2-tailed) & .377 & .106 & .496 & .659 & .460 & .172 & .647 & .642 \\
\hline & $\mathrm{N}$ & 13 & 13 & 13 & 13 & 13 & 13 & 13 & 13 \\
\hline \multirow[t]{3}{*}{ extroversion } & Pearson & .404 & .503 & -.416 & -.331 & -.277 & .518 & -.147 & -.442 \\
\hline & Sig. (2-tailed) & .171 & .079 & .158 & .269 & .359 & .070 & .632 & .130 \\
\hline & $\mathrm{N}$ & 13 & 13 & 13 & 13 & 13 & 13 & 13 & 13 \\
\hline \multirow[t]{3}{*}{ openness } & Pearson & $.736^{* * *}$ & $.708^{* *}$ & .179 & .208 & .266 & $.634 *$ & -.306 & -.284 \\
\hline & Sig. (2-tailed) & .004 & .007 & .558 & .495 & .380 & .020 & .310 & .347 \\
\hline & $\mathrm{N}$ & 13 & 13 & 13 & 13 & 13 & 13 & 13 & 13 \\
\hline \multirow[t]{3}{*}{ agreeability } & Pearson & $.625^{*}$ & .282 & .532 & $.650^{*}$ & $.671 \%$ & .115 & $-.556 *$ & .182 \\
\hline & Sig. (2-tailed) & .022 & .351 & .061 & .016 & .012 & .708 & .049 & .551 \\
\hline & $\mathrm{N}$ & 13 & 13 & 13 & 13 & 13 & 13 & 13 & 13 \\
\hline \multirow{3}{*}{$\begin{array}{l}\text { conscientiousne } \\
\text { SS }\end{array}$} & Pearson & $.675^{*}$ & .470 & .276 & .260 & .174 & .223 & -.343 & .346 \\
\hline & Sig. (2-tailed) & .011 & .106 & .362 & .390 & .570 & .464 & .251 & .247 \\
\hline & $\mathrm{N}$ & 13 & 13 & 13 & 13 & 13 & 13 & 13 & 13 \\
\hline
\end{tabular}

Table 5. Correlations between FFI personality characteristics and network position in the trust network as well as between trust ratings given and received (dc_trust_dl=actor degree centrality on day 1 in the trust network, bc trust_dl=actor betweeness centrality on day 1 in the trust network, dc_notrust_d1=actor degree centrality on day 1 in the distrust network, pos_rcvd=number of statements of trust received, pos_sent=numbers of statements of trust given, neg_rcvd=number of statements of distrust received, neg_sent=numbers of statements of distrust given)

The more open a person is, the higher is her/his degree centrality in the trust network, i.e. the more people trust her/him. The more open a person is, the higher is her/his betweenness centrality in the trust network, i.e. the more influential people trust her/him. This means that people who are more open for new things are also more central in the trust network, and they express more trust in other people $\left(\mathrm{R}=0.634^{*}\right)$

Agreeability seems to be a double-edged sword, in the sense that always saying "yes" on occasion might lead to lower trust. The more agreeable a person is, the higher is her/his degree centrality in the trust network, i.e. the more people trust her/him. But also, the more agreeable a person is, the higher her/his betweenness centrality in the distrust network, i.e. the more influential people distrust her/him. Agreeable people are therefore central in both the trust and non-trust network. On the other hand, the more agreeable people are, the less expressions of non-confidence they receive $\left(\mathrm{R}=-0.556^{*}\right)$. This means that in general, agreeable people are more trusted, but not by influential people.

\subsection{Team Creativity and Interpersonal Trust}

Our findings indicate that trust explains a lot about the creativity in teams. We accumulated the expressions of confidence per team over all team members as a proxy of the social capital of the team. The more team members receive statements of confidence (mean_pos_recvd) and give 
statements of confidence (mean_pos_snt), and the fewer statements of non-confidence (mean_neg) they receive, the higher their team creativity. At the same time, the more statements of confidence in total they give or receive (mean_pos).

\begin{tabular}{|l|r|r|r|r|r|} 
& \multicolumn{1}{|c|}{} & \multicolumn{2}{c|}{$\begin{array}{c}\text { Standardized } \\
\text { Coefficients }\end{array}$} & \\
\cline { 2 - 3 } & \multicolumn{1}{|c|}{ Bnstandardized Coefficients } & Std. Error & Beta & t & Sig. \\
\hline (Constant) & 5.703 & 1.166 & & 4.891 & .016 \\
mean_pos_recvd & .652 & .226 & 5.155 & 2.879 & .064 \\
mean_pos_sent & .760 & .247 & 5.760 & 3.079 & .054 \\
mean_pos & -.684 & .245 & -8.460 & -2.791 & .068 \\
mean_neg_rcvd & -.198 & .066 & -.784 & -3.003 & .058 \\
mean_neg & .021 & .007 & .693 & 3.084 & .054 \\
\hline
\end{tabular}

a. Dependent Variable: creativity

Table 6. Regression coefficients of trust ratings given and received, regressed against creativity (mean_pos_rcvd=mean number of statements of trust received per team, mean_pos_sent=mean number of statements of trust given per team, mean_pos=mean numbers of statements of rust given and received per team, mean_neg_rcvd=mean number of statements of distrust received per team, mean_neg $=$ mean numbers of statements of distrust given and received per team)

We regressed the mean positive and negative confidence the 15 participants expressed in each other aggregated per team against peerranked creativity of each project. Table 6 shows the results, the adjusted $\mathrm{R}$ squared is quite high with 0.748 . To put it in other words, the more team members are willing to confide into each other, the more creative their collaborative output.

The same relationship also predicts the quality of the teamwork. Regressing the mean positive trust team members expressed in each other as well as the mean unwillingness to not confide into each other leads to an adjusted $\mathrm{R}$ square of 0.730 .

\subsection{Team Creativity and Social Network Position in the f2f Network}

Table 8 shows the total number of times members of each team were facing each other during the entire week using the infrared sensors. We summed up all interactions between the corresponding badges of all team members into one number per badge pair. 
Measuring Social Capital in Creative Teams Through Sociometric Sensors

\begin{tabular}{|ll|r|r|r|r|r|r|}
\hline & & tot_IR & mean_IR & weight_IR & tot_radio & mean_radio & weight_radio \\
\hline creativity & Pearson & .580 & .650 & $\mathbf{. 6 9 2}^{*}$ & -.255 & -.091 & .076 \\
& Correlation & & & & & & \\
& Sig. (2-tailed) & .102 & .058 & .039 & .508 & .816 & .846 \\
& $\mathrm{~N}$ & 9 & 9 & 9 & 9 & 9 & 9 \\
\hline quality & Pearson & .215 & .207 & .203 & .268 & .417 & .361 \\
& Correlation & .578 & .593 & .601 & .485 & .264 & .339 \\
& Sig. (2-tailed) & 9 & 9 & 9 & 9 & 9 & 9 \\
N & 9 & & & 9 & 9 \\
\end{tabular}

Table 7. Correlations between creativity, quality and accumulated interactions per team, measured through the IR and radio sensors (tot_IR=sum of IR signals picked up per team, mean_IR=mean number of IR signals per team, weight_IR=weighted mean of IR signals per team (=tot_IR/ $\left(\begin{array}{c}\text { \# team members } \\ 2\end{array}\right)$, tot_radio=sum of radio signals picked up per team, mean_radio $=$ mean number of radio signals per team, weight_radio=weighted mean of radio signals per team)

As Table 7 illustrates there is significant positive correlation $(0.692 *)$ between the number of times team members are facing each other, and the creativity of their work results. At the same time, there is (non-significant) negative correlation between the proximity measured by the radio sensors and the creativity of their work output. This means that the more team members are facing each other, and the less close they are to each other, the more creative is their work output.

Table 8 displays the regression results, illustrating that the creativity of teams can be explained to a large extent $(\mathrm{R} \mathrm{sq} \operatorname{adj}=0.985)$ by the team members' trust and distrust into each other as well as how they are facing each other and how physically close they are during their work.

\begin{tabular}{|c|c|c|c|c|c|c|}
\hline & & \multicolumn{2}{|c|}{ Unstandardized Coefficients } & \multirow{2}{*}{$\begin{array}{c}\text { Standardized } \\
\text { Coefficients } \\
\text { Beta } \\
\end{array}$} & \multirow[b]{2}{*}{$\mathrm{t}$} & \multirow[b]{2}{*}{ Sig. } \\
\hline \multicolumn{2}{|c|}{ Model } & $\mathrm{B}$ & Std. Error & & & \\
\hline \multirow[t]{7}{*}{1} & (Constant) & 6.981 & .332 & & 21.033 & .002 \\
\hline & mean_pos_rcvd & .126 & .014 & .947 & 9.252 & .011 \\
\hline & mean_pos_sent & .226 & .015 & 1.715 & 14.756 & .005 \\
\hline & mean_neg_sent & .095 & .006 & 2.942 & 14.916 & .004 \\
\hline & mean_neg_rcvd & -.511 & .034 & -2.020 & -14.999 & .004 \\
\hline & weight_IR & -.026 & .002 & -2.390 & -10.953 & .008 \\
\hline & mean_radio & .000 & .000 & -.714 & -12.102 & .007 \\
\hline
\end{tabular}

a. Dependent Variable: creativity

Table 8. Regression coefficients of aggregated team IR and radio signals picked up by sociometric badges combined with aggregated confidence and non-confidence sent and received, regressed against creativity 
A different picture emerges for the quality of the output, where both facing other team members a lot, and being physically close helps. The correlations are all weaker, and non-significant however, so much more analysis is needed to better understand this effect.

To sum up our findings, we have confirmed our hypothesis that accumulated social capital of a team, measured as the sum of the expression of trust between team members, and the amount of interaction between team members, predicts the creativity and quality of their team output.

\section{Discussion}

In this paper we investigated the factors enabling collective creativity, providing empirical evidence and a new framework to recognize personality traits and social behaviors able to maximize team performance and creativity. We recognize and optimize creative groups by looking at individual and collective patterns of social behavior through sociometric badges and correlating this behavior with the creativity and quality of the group outcome. The moderating variables impacting the ability of groups to deliver high quality results are face-to-face interaction and eye contact, propensity to trust, and the group members' personality traits. The results support our hypothesis that both trust between team members and the amount of interaction between them are correlated with higher collective creativity.

We found that individual traits - such as being open for new things - and social skills - such as team members' willingness to confide into each other - are correlated with a more creative collaborative output. Our study extends the understanding of the "creativity-relevant skills" that determine a person's creative outcome, as described by Amabile (1983).

Besides confirming that specific traits are linked to higher collective creativity, our results show other interesting correlations between individual traits. Based on the expressions of non-confidence received by members, we found that agreeable people are more trusted by other teammates, but not by influential ones. On the other hand, we observed that influential people tend to trust people with an open personality. As noted by scholars in the leadership field (Judge et al., 2002), while the link between openness and leadership is clearly defined, the connection between agreeableness and leadership is ambiguous. Some authors found that interpersonal sensitivity and altruism - which are hallmarks of an agreeable personality - are related to leadership. Other studies found that 
"need for affiliation" - another trait of agreeability - is negatively related to leadership. In contrast, influential people tend to be more open and they seem to be attracted by people showing creative and divergent thinking. This might explain our result that prominent members - in a formal or informal leadership position - trust people similar to them based on their openness and agreeability behavior.

Our study proposes new relationships among creativity-relevant skills and offers a novel perspective to identify individual and collective behaviors fostering team creativity. Our findings indicate that social networks as the expression of social capital create trust and improve creativity. Looking at the most between actors in the face-to-face network allows recognizing the most trustworthy team members. This is aligned with the results of other studies indicating that people look at third parties' connections to decide whether to trust each other (Ferrin et al., 2006).

The findings of this study provide first hints that interacting with many central people might predict openness for new ideas. The more members are facing each other, the more open they are for new things and the higher the creativity of their work results. Other interesting correlations indicate that the more members interact with many teammates at one moment, and then interact with only a few members the next moment, the less they are trusted. This result might indicate that members who are less trusting show a larger variation in their face-to-face communication.

It seems that to build mutual trust, team members prefer to interact with a small and less diverse social network, where the prominent position is held by more open and trustworthier people.

There is still a lack of extensive research on the determinants of interpersonal trust in an organizational network. Our study provides empirical evidences to help explain how teams can be more creative by increasing their interpersonal relationships and trust network. Our findings confirm work by others (Grant and Berry, 2011) showing that individuals who are more prosocial are also more creative. Using sociometric badges gives us a new and unique way to measure accumulated prosocial behavior as social capital.

How could these results be used to develop more creative teams? Building up trust within the team seems to increase both creativity and quality. This corresponds well with earlier research emphasizing the role trust plays to increase team performance. And as we have found in this project, interacting a lot with your fellow team members, facing them and looking them into the eyes seems to be a good way to increase mutual trust. 


\section{Conclusions and Limitations}

This research proposes a new method to study interpersonal trust and creativity based on the use of both traditional techniques (surveys) and innovative methods (sociometric badges) to collect data on human behavior. Although the wearable sensors are quite unobtrusive as they do not record a complete conversation between actors, a person's movements and interactions can still be tracked. This implies that researchers are advised to design experiments able to minimize the impact on people's privacy. At the same time, they need to control for possible changes in human behaviors due to the awareness of being observed to avoid the Hawthorne effect (Landsberger, 1958).

The main limitation of our project is the small sample size of our study subjects, leading to some insignificant results, and lack of enough data to do more sophisticated analysis. This means that in future work we both hope to be able to study larger groups in a variety of creative tasks. We are currently working on different projects, among others studying social signals of software developers in distributed and co-located teams, of researchers in the health care area, school children participating in extracurricular science activities, and Jazz musicians.

We are convinced that we are only at the beginning of a new era of research, trying to better understand what drives team creativity by analyzing "honest signals" of team members. While our results are preliminary, they nevertheless seem to indicate that mutual trust is essential for teamwork, and that there is no substitute for face-to-face interaction to build up this trust.

\section{References}

Amabile, T.M. (1983) 'The social psychology of creativity: A componential conceptualization', Journal of Personality and Social Psychology, Vol. 45, No.2, pp. 357-376.

Amabile, T.M. (1996) Creativity in Context: Update to the Social Psychology of Creativity, Westview Press, Boulder, CO.

Feist, G.J. (1999) 'Influence of personality on artistic and scientific creativity', In R. Sternberg, (Ed.): Handbook of Creativity, Cambridge University Press, New York, NY.

Ancona, D. G., Bresman, H.M. and Kaeufer, K. (2002) 'The comparative advantage of X teams', Sloan Management Review, Vol. 43, pp. 3339. 
Barron, F. (1969) Creative person and creative process, Holt, Rinehart and Winston, New York, NY.

Barron, F., and Harrington, D. (1981) 'Creativity, intelligence, and personality', In M. Rosenzweig and L. Porter (Eds.): Annual review of psychology, Vol. 32, pp. 439-476, Palo Alto, CA: Annual reviews.

Borgatti, S.P. (2002) 'A Statistical Method for Comparing Aggregate Data Across a priori Groups', Field Methods, Vol. 14, No.1, pp. 88-107.

Choi, H.S. and Thompson, L. (2005) Old wine in a new bottle: Impact of membership change on group creativity, Organizational Behavior and Human Decision Processes, Vol. 98, No. 2, pp. 121-132.

Collins, R. (2005) Interaction Ritual Chains. Princeton University Press.

Csikszentmihalyi, M. (1997) Creativity: Flow and the Psychology of Discovery and Invention, Harper Perennial, New York, NY.

Cummings, J. and Kiesler, S. (2008) 'Who Collaborates Successfully? Prior Experience Reduces Collaboration Barriers in Distributed Interdisciplinary Research', Proc. of the Conference CSCW'08, San Diego, CA.

Dirks K.Y. (1999) 'The Effects of Interpersonal Trust on Work Group Performance', Journal of Applied Psychology, Vol. 84, pp. 445-455.

Ferrin, D. and Shah, P. (1997) 'Trust, cooperation, and conflict in groups: A social network analysis of MBA task force teams', Proc. of the 1997 Academy of Management Meeting, Boston, MA.

Ferrin D.L., Dirks K.T. and Shah P.P., (2006) 'Direct and Indirect Effects of Third-Party Relationships on Interpersonal Trust', Journal of Applied Psychology, Vol. 91, No. 4, pp. 870-883.

Falchikov, N. (1986) 'Product Comparisons and Process Benefits of Collaborative Peer Group and Self Assessments', Assessment and Evaluation in Higher Education, Vol. 11, pp. 146-166.

Friedlander, F. (1970) 'The primacy of trust as a facilitator of further group accomplishment', Journal of Applied Behavioral Science, Vol. 6, pp. 387-400.

Gloor, P., Laubacher, R., Dynes, S., and Zhao, Y. (2003) 'Visualization of Communication Patterns in Collaborative Innovation Networks Analysis of some W3C working groups', Proc. ACM CKIM, New Orleans. 
P. Gloor et. al.

Gloor, P., Fischbach, K., Fuehres, H., Lassenius, C., Niinimäki, T., Olguin Olguin, D., Pentland, A., Piri A. and Putzke, J. (2010) 'Towards "Honest Signals" of Creativity - Identifying Personality Characteristics Through Microscopic Social Network Analysis', Proc. of the COINs 2010, Collaborative Innovations Networks Conference, Savannah GA.

Gloor, P. Oster, D. Raz, O. Pentland and A. Schoder, D. (2010) 'The Virtual Mirror - Reflecting on Your Social and Psychological Self to Increase Organizational Creativity', Journal on International Studies of Management \& Organization, M.E Sharpe, Vol. 40, No. 2.

Goncalo J.A. and Staw B.M. (2006) 'Individualism-collectivism and group creativity', Organizational Behavior and Human Decision Processes, Vol. 100, pp. 96-109.

Grant, A. M. and Berry, J. W. (2011) 'The Necessity of Others Is the Mother of Invention: Intrinsic and Prosocial Motivations, Perspective Taking, and Creativity', Academy of Management Journal, Vol. 54, No.1, pp. 73-96.

Hackman, J. R. and Katz, N. (2010) 'Group behavior and performance', In S. T. Fiske, D. T. Gilbert, and G. Lindzey (Eds.): Handbook of social psychology (5th ed.), pp. 1208-1251, Wiley, New York, NY.

Helson, R. (1996) 'In search of the creative personality', Creativity Research Journal, Vol. 9, pp. 295-306.

Hough, L. M. (1992) "The "big five" personality variables - construct confusion: Description versus prediction', Human Performance, Vol. 5, No. 1, pp. 139-155.

Judge T.A., Ilies R., Bono J.E. and Gerhardt M.W. (2002) 'Personality and Leadership: a qualitative and quantitative review', Journal of Applied Psychology, Vol. 87, No.4, pp. 765-780.

Landsberger, H.A. (1958) Hawthorne Revisited: Management and the Worker, Its Critics, and Developments in Human Relations in Industry, Cornell University, Ithaca, New York.

McAllister, D. (1995) 'Affect- and cognition-based trust as foundations for interpersonal cooperation in organizations', Academy of Management Journal, Vol. 38, pp. 24-59.

Nemoto, K., Gloor, P. and Laubacher, R. (2011) 'Social Capital Increases Efficiency of Collaboration among Wikipedia Editors', Proc. of the 22nd ACM Conference on Hypertext and Hypermedia. 
Olguín Olguín, D. (2007) 'Sociometric Badges: Wearable Technology for Measuring Human Behavior', MAS Thesis. Massachusetts Institute of Technology, Cambridge, MA.

Olguin Olguin, D., Gloor, P. and Pentland, A. (2009) 'Capturing Individual and Group Behavior with Wearable Sensors', Proc AAAI 2009 Spring Symposium, Stanford.

Olguín Olguín, D., and Pentland, A.S. (2010) 'Sensor-based organisational design and engineering', International Journal of Organisational Design and Engineering, Vol. 1, No. 1/2, pp. 69-97.

Opsahla, T. Filip Agneessens and F. Skvoretz, J. (2010) 'Node centrality in weighted networks: Generalizing degree and shortest paths', Social Networks, Vol.32, pp. 245-251.

Pentland, A.S. (2007) 'On the collective nature of human intelligence', Adaptive Behavior, Vol. 15, No.2, pp. 189-198.

Pentland, A.S. (2008) Honest Signals, How They Shape Our World, MIT Press, Cambridge MA.

Perry-Smith, J. E., and Shalley, C. E. (2003) 'The social side of creativity: A static and dynamic social network perspective', Academy of Management Review, Vol. 28, pp. 89-106.

Putnam, R. D. (2001) Social Capital: Measurement and Consequences. Isuma: Canadian Journal of Policy Research 2 (Spring 2001): 41-51.

Sawyer, C. (2007) Group Genius: The Creative Power of Collaboration, Basic Books, New York, NY.

Sternberg, R. J., and Lubart, T.I. (1999) 'The Concept of Creativity: Prospects \& Paradigms', In R.J. Sternberg (Ed.): Handbook of creativity, pp.313-335, Cambridge University Press, New York.

Uzzi, B., and Spiro, J. (2005) 'Collaboration and Creativity: The Small World Problem', American Journal of Sociology, Vol. 111, No.2, pp. 447-504.

Woodman, R., and Sherwood, J. (1980) 'The role of team development in organizational effectiveness: A critical review', Psychological Bulletin, Vol. 88, pp. 166-186.

Zhou, J. (2003) 'When the presence of creative coworkers is related to creativity: Role of supervisor close monitoring, developmental feedback, and creative personality', Journal of Applied Psychology, Vol. 88, pp. 413-422. 
P. Gloor et. al.

Zhou J., Shin S.J., Brass D.J., Choi J., and Zhang Z.X. (2009) 'Social networks, personal values, and creativity: evidence for curvilinear and interaction effects', Journal of Applied Psychology, Vol. 94, No.6, pp. 1544-1552.

Wasserman, S. and Faust, K. (1994) Social Network Analysis: Methods and Applications, Cambridge University Press, Cambridge, UK. 